\title{
Carbonation of Portland Cement Studied by Diffuse Reflection Fourier Transform Infrared Spectroscopy
}

\author{
Rikard YImén*, and Ulf Jäglid
}

(Received August 27, 2012, Accepted April 4, 2013)

\begin{abstract}
Carbonation is a natural ageing process for cement. This study focuses on how the carbonation rate varies with selected hydration times and atmospheric conditions during the early stages of reacting dried cement paste. Diffuse reflection Fourier transform infrared spectroscopy is shown to be a suitable technique to monitor the formation of carbonates in cement. Combined with a previously developed freeze drying technique, carbonation can be studied at specific hydration stages. In ambient air both calcium hydroxide and calcium silicate hydrate $(\mathrm{C}-\mathrm{S}-\mathrm{H})$ in cement are carbonated. Increased hydration time enhances the carbon dioxide uptake, which indicates that the calcium in the hydration products reacts more easily than the calcium in the clinker phase. In a humid $\mathrm{CO}_{2}$ atmosphere, the carbonation process is so pronounced that it decomposes $\mathrm{C}-\mathrm{S}-\mathrm{H}$ into calcium carbonate and silica. In a moist $\mathrm{N}_{2}$ atmosphere no carbonation occurs, but the sulfate chemistry of the cement seems to be affected due to the formation of ettringite.
\end{abstract}

Keywords: carbonation, Portland cement, infrared spectroscopy, cement hydration, C-S-H.

\section{Introduction}

Portland cement is widely used for the construction of concrete buildings. The dry Portland cement powder reacts with water to form the matrix that binds the aggregates in concrete together. To be able to predict the properties of the final structure, it is vital to understand the water-cement interaction. However, during its time of service the concrete is exposed to an environment that will alter its properties and modify its structure, both physically and chemically. A very important chemical substance that reacts with the cement matrix in concrete is carbon dioxide. It can cause carbonation of both the clinker phases and the products formed during the hydration of the cement, such as calcium hydroxide and calcium silicate hydrate gel $(\mathrm{C}-\mathrm{S}-\mathrm{H})$. It is therefore important to take the early carbonation of $\mathrm{C}-\mathrm{S}-\mathrm{H}$ into account when handling samples in the laboratory, since the studied properties may change and affect the results.

The carbonation of Portland cement is a naturally occurring process during the ageing of a concrete structure; it changes the physical and chemical properties of the cement. During the carbonation process $\mathrm{CaCO}_{3}$ is formed and other carbonate phases are expected to be negligible. The carbonation may

Department of Chemistry and Biotechnology,

Environmental Inorganic Chemistry, Chalmers

University of Technology, 41296 Göteborg, Sweden.

*Corresponding Author;

E-mail: rikard.ylmen@chalmers.se

Copyright $($ The Author(s) 2013. This article is published

with open access at Springerlink.com also induce corrosion of steel reinforcing bars, due to the reduction of alkalinity, which may cause severe damage to a structure.

The objective of this study is to improve the understanding of the carbonation processes in cement by monitoring the changes in characteristic infrared vibration modes that are coupled to the process. This is done by monitoring the carbonation of all samples with diffuse reflection Fourier transform spectroscopy (DR-FTIR), a technique that is suited to determining initial cement chemistry (Ylmén et al. 2009).

By combining this with a freeze drying technique (Ylmén et al. 2008), carbonation can be studied at different quenched hydration stages. In this work short hydration times has been studied, from $10 \mathrm{~min}$ to $8 \mathrm{~h}$.

This method of studying the carbonation of cement has previously not been applied.

It is well known that the carbonate ion has four characteristic vibration modes in the mid-IR region. There are three common polymorphs of anhydrous $\mathrm{CaCO}_{3}$ : calcite, aragonite and vaterite. The characteristic vibration modes of the carbonate ion in these polymorphs lie approximately at $698-745 \mathrm{~cm}^{-1}\left(v_{4}\right), 842-910 \mathrm{~cm}^{-1}\left(v_{2}\right), 1,070-1,085 \mathrm{~cm}^{-1}$ $\left(v_{1}\right)$ and $1,425-1,590 \mathrm{~cm}^{-1}\left(v_{3}\right)$ (Xyla and Koutsoukos 1989; Gunasekaran et al. 2006; Frech et al. 1980; Rutt and Nicola 1974; Vagenas et al. 2003). There are also combination bands such as $v_{4}+v_{1}$ at $1,800 \mathrm{~cm}^{-1}, v_{4}+v_{3}$ at $2,500 \mathrm{~cm}^{-1}$ and $2 v_{3}$ at $2,900 \mathrm{~cm}^{-1}$.

Water absorbs infrared radiation between 1,600 and $1,700 \mathrm{~cm}^{-1}$ due to its bending vibration $v_{2}$ (Trezza and Lavat 2001; Richard et al. 2006; Mollah et al. 2003). It also absorbs this radiation in the range $3,000-3,700 \mathrm{~cm}^{-1}$ as this 
corresponds to the $\mathrm{O}-\mathrm{H}$ stretching region. The hydroxide containing compounds also absorb in this range, such as $\mathrm{Ca}(\mathrm{OH})_{2}$ at 3,643 $\mathrm{cm}^{-1}$ (Björnström 2005; Delgado et al. 1996; Yu et al. 1999).

In this study the samples were freeze-dried prior to exposure to quench the hydration process (Ylmén et al. 2008, 2009). A set of samples was exposed to ambient air for 19 days to simulate storage in open containers. The decision to stop the exposure to ambient air after 19 days was based on the observation that the carbonation had, more or less, ceased after 8 days.

Another set of samples was exposed to a highly carbonating environment with pure carbon dioxide of $75 \%$ relative humidity. The exposure to pure carbon dioxide was stopped after 4 days since the samples showed carbonation equal to that of 19 days of exposure in ambient air. Reference samples were exposed to pure nitrogen gas with $75 \%$ relative humidity to examine the effect of moisture. The $75 \%$ relative humidity was chosen as it has been observed that the hydration of the cement is very slow, but the carbonation rate is high at this humidity (Mejlhede Jensen et al. 1999; Houst 1996).

The idea behind having a nitrogen atmosphere was to determine whether any of the observed changes during exposure to ambient air was only an effect of the presence of water in the air. The exposure to a nitrogen atmosphere was stopped after 3 days since the samples only showed small changes during this time, whereas the samples exposed to ambient air showed significant changes after only $3 \mathrm{~h}$.

\section{Method}

The cement used was a limestone type "byggcementStd PK Skövde CEM II/A-LL 42,5 R”. Test samples were prepared by mixing $100 \mathrm{~g}$ cement with $40 \mathrm{~g}$ de-ionized water $(\mathrm{w} / \mathrm{c}=0.4)$ manually for $1 \mathrm{~min}$. The cement pastes were cast in plastic cups, sealed with lids, and then hydrated at room temperature $(295 \mathrm{~K})$. At predetermined times the hydration was stopped by immersion of the samples in liquid nitrogen. The samples were then freeze-dried overnight. The freeze-drying technique has been successfully used in previous studies to quench the hydration (Ylmén et al. 2008, 2009). To minimize the effect of structural differences between the samples, all the hydrated samples were crushed before exposure. The hydrated samples were then exposed to one of the three different environments described below, and subsequently analyzed using DR-FTIR spectroscopy.

- Ambient air with 50\% humidity: The samples were scanned with DR-FTIR spectroscopy several times during a time period of 19 days. As a comparison, an unhydrated sample was also exposed at the same conditions.

- $\mathrm{N}_{2}$ atmosphere with $75 \%$ humidity: The samples were scanned with DR-FTIR after 3 days of exposure.

- $\mathrm{CO}_{2}$ atmosphere with $75 \%$ humidity: The samples were scanned with DR-FTIR spectroscopy after 4 days of exposure.

The $75 \%$ atmospheric humidity was obtained by letting a small flow $\left(\sim 1 \mathrm{dm}^{3} / \mathrm{h}\right)$ of pure $\mathrm{CO}_{2}$ gas or $\mathrm{N}_{2}$ gas pass through water, saturated with $\mathrm{NaCl}$, into the chamber containing the samples. After exposure the samples were measured with diffuse reflection Fourier transform infrared spectroscopy using a Nicolet Magna-IR 560 with an insert cell for diffuse reflection spectroscopy. The measurement range lies between 400 and $4,000 \mathrm{~cm}^{-1}$ with a nominal resolution of $2 \mathrm{~cm}^{-1}$

\section{Results}

The carbonation results are described with respect to the three sets of environmental conditions. The evaluation is made primarily from the characteristic infrared active vibration peaks of carbonate and hydroxide containing

Table 1 Assignments to the peaks observed in Figs. 1, 2, 3, 4, 5, and 6 .

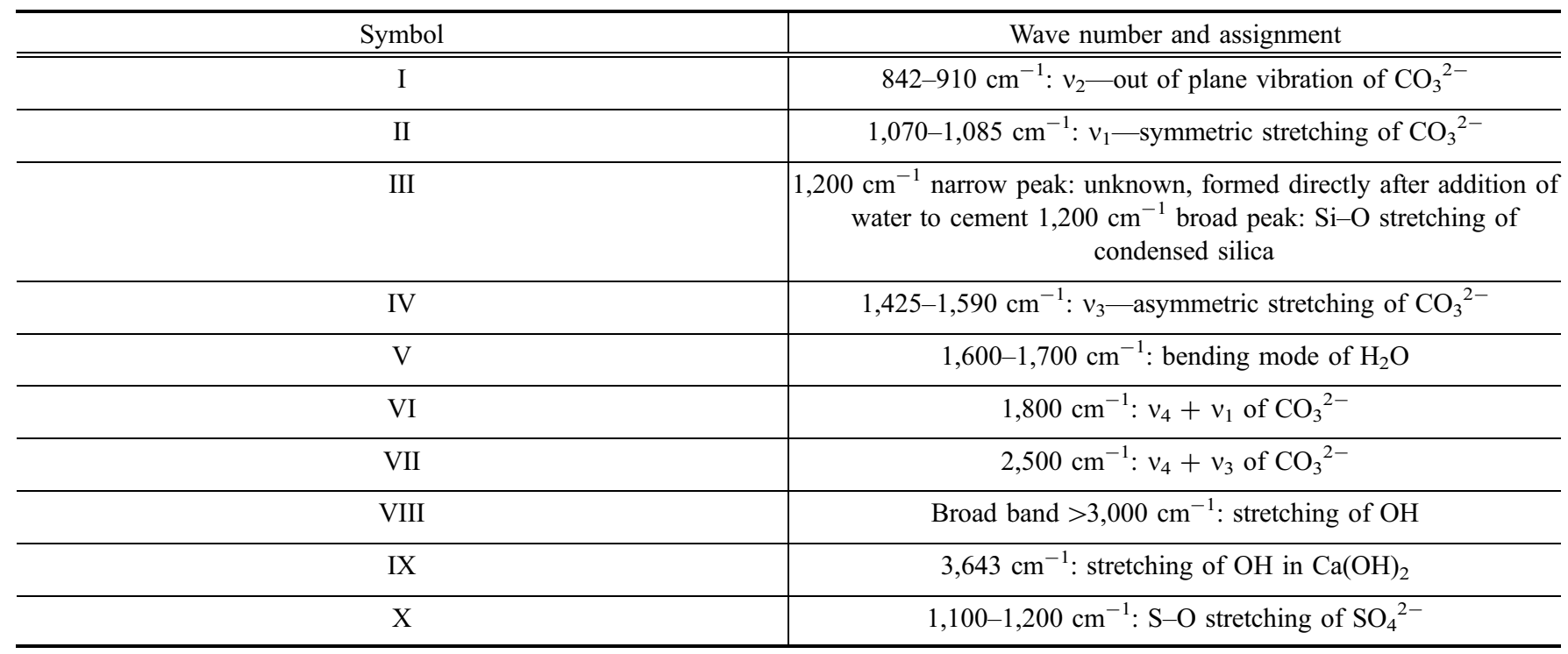




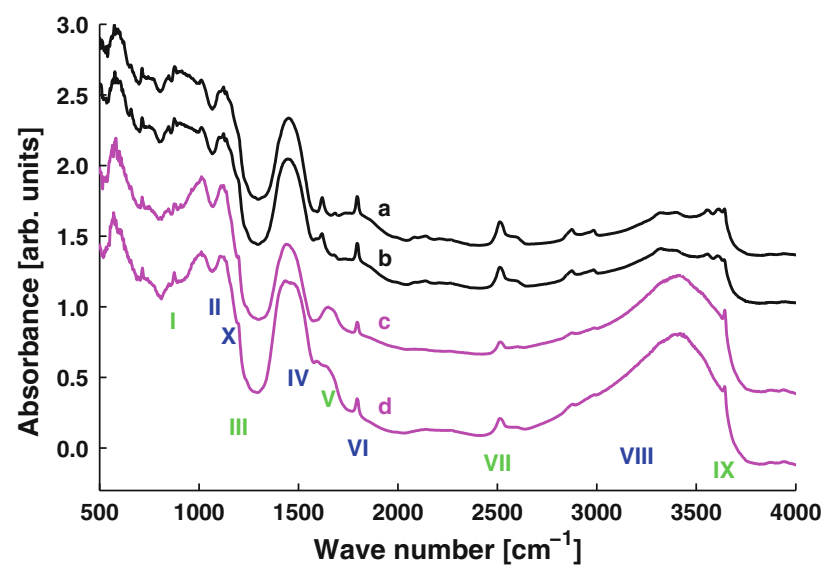

Fig. 1 DR-FTIR spectra of (a) unhydrated cement exposed to ambient air for $10 \mathrm{~min}$. (b) unhydrated cement exposed to ambient air for 19 days. (c) Cement hydrated for $8 \mathrm{~h}$ and then exposed to ambient air for $10 \mathrm{~min} .(d)$ Cement hydrated for $8 \mathrm{~h}$ and then exposed to ambient air for 19 days. The assignments and characterizations of the peaks and bands, marked with $I-X$ in the spectra, are presented in Table 1.

compounds. The assignments of the observed peaks are given in Table 1. Figure 1 shows the difference between the spectra of an unexposed sample and an exposed one. It may be noted that the difference is rather small. In addition, there are also many peaks in the spectra that do not show any changes during the exposure. It is beneficial to subtract a suitable reference spectrum to see more clearly the effect of exposure. To illustrate this, the difference between spectrum (a) and (b) in Fig. 1 is shown as the bottom spectrum presented in Fig. 2a. Similarly, the difference between spectrum (c) and (d) in Fig. 1 is the bottom spectrum shown in Fig. 2e.

\subsection{Ambient Air}

The DR-FTIR spectra are presented for unhydrated samples in Fig. 2a. Figure 2b-e shows samples hydrated during time intervals from $10 \mathrm{~min}$ to $8 \mathrm{~h}$. All of the samples were exposed to ambient air. To remove all signatures that are not the result of exposure, the spectrum after $10 \mathrm{~min}$ of exposure, within each exposure series, was subtracted from all the other spectra. The peaks at 1,800 and $2,500 \mathrm{~cm}^{-1}$ and the three bands rising in the region of $1,300-1,700 \mathrm{~cm}^{-1}$ are related to the carbonation process. The peaks at 1,410 and $1,535 \mathrm{~cm}^{-1}$ increase initially, whereas the peak at $1,580 \mathrm{~cm}^{-1}$ starts to develop later. The humps at $\sim 1,650$ and 2,700-3,700 $\mathrm{cm}^{-1}$ are associated with an increase of water. There is also a dip at $3,643 \mathrm{~cm}^{-1}$ due to a decreased amount of $\mathrm{Ca}(\mathrm{OH})_{2}$.

To evaluate the relative extent of carbonation, the peak area in the region of $1,300-1,700 \mathrm{~cm}^{-1}$ has been integrated for all samples, where the zero-level was set at $1,300 \mathrm{~cm}^{-1}$. The results of the integration are shown in Fig. 3.

\section{$3.2 \mathrm{~N}_{2}$ and $\mathrm{CO}_{2}$ Environment with $75 \%$ Humidity}

The impact of the $\mathrm{N}_{2}$ and $\mathrm{CO}_{2}$ atmospheres on the dried cement paste is shown for selected hydration times in Fig. 4. The spectrum of an unhydrated and unexposed cement sample was subtracted from all hydrated spectra displayed in Fig. 4.

To see more clearly the effect of carbonation, the spectrum of a hydrated, but unexposed, sample was subtracted from the spectrum of a sample exposed to humid $\mathrm{N}_{2}$. It should be noted that both samples have the same hydration time. The resulting spectra are shown in Fig. 5. All samples show a clear shift from $\sim 1,180$ to $\sim 1,100 \mathrm{~cm}^{-1}$, most likely due to the reformation of sulfates (Vazquez-Moreno and BlancoVarela 1981). There is also an increase in water content indicated by broad humps centred at $\sim 1,670$ and $3,430 \mathrm{~cm}^{-1}$ and also a peak at $3,630 \mathrm{~cm}^{-1}$. These absorption bands fit well with the characteristic infrared modes of crystal water in ettringite (Pajares et al. 2003).

There is a much larger alteration in the infrared spectra when the dried cement paste is exposed to a humid $\mathrm{CO}_{2}$ than when exposed to a humid $\mathrm{N}_{2}$ atmosphere (Fig. 4). To see more clearly the effect of carbonation, the spectrum of a hydrated, but unexposed, sample was subtracted from a sample exposed to $\mathrm{CO}_{2}$. It should be emphasized that both samples have the same hydration time. The resulting spectra are shown in Fig. 6.

The peaks at 856, 875, 1080, 1410, 1540, 1795 and $2513 \mathrm{~cm}^{-1}$ can be observed in all of the spectra and were assigned to $\mathrm{CaCO}_{3}$. In a $\mathrm{CO}_{2}$ rich atmosphere there is a noticeable decline in $\mathrm{Ca}(\mathrm{OH})_{2}$, seen as a dip at $3,643 \mathrm{~cm}^{-1}$ in Fig. 6. It is interesting to note that for the 8-h hydration sample there is also a dip at $\sim 950-1,100 \mathrm{~cm}^{-1}$ corresponding to the peaks for $\mathrm{C}-\mathrm{S}-\mathrm{H}$ (Ylmén et al. 2009). A decrease can also be seen in the $\mathrm{OH}$-stretching region $\left(3,000 \mathrm{~cm}^{-1}\right)$ where a broad dip has formed, corresponding to the signature of $\mathrm{C}-\mathrm{S}-\mathrm{H}$. The spectra for all hydration times also show a peak at $1,200 \mathrm{~cm}^{-1}$ with a narrow dip at the same position. The band at $\sim 1,650 \mathrm{~cm}^{-1}$, together with the increased intensity in the $\mathrm{OH}$-stretching region, indicates absorption of water for all hydration times.

\section{Discussion}

The variation of the carbonation rate versus hydration time was examined under three environmental conditions during the first $8 \mathrm{~h}$ of hydration. The relative amount of carbonation was determined from the integrated area between 1,300 and $1,700 \mathrm{~cm}^{-1}$. The effect of the different environmental conditions is shown in Fig. 7. In humid $\mathrm{CO}_{2}$ atmosphere the unexposed sample for each hydration time was used as reference and the spectra are presented in Fig. 6. In the 19-days exposure to ambient air, the sample exposed for $10 \mathrm{~min}$ was used as reference for each hydration time. These spectra are displayed in Fig. 2e. Inhumid $\mathrm{N}_{2}$ atmosphere, the unexposed sample for each hydration time was used as reference. The spectra are shown in Fig. 5.

It can be concluded from Figs. 3 and 7 that longer hydration times for the cement paste result in faster $\mathrm{CaCO}_{3}$ formation when the dried and ground paste is exposed to air. However, this relationship does not seem to be valid for the accelerated carbonation in a humid $\mathrm{CO}_{2}$ atmosphere. 

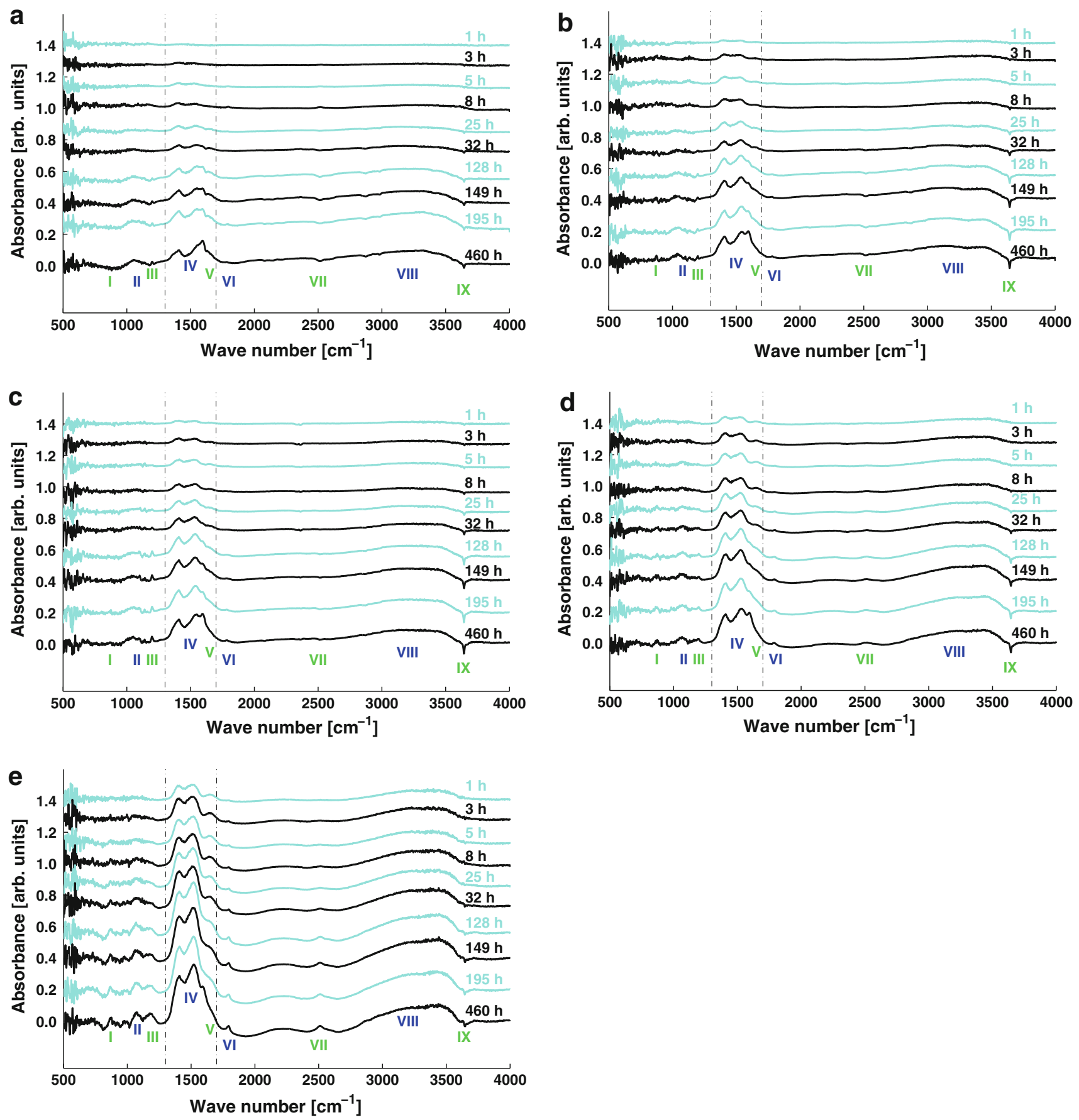

Fig. 2 DR-FTIR spectra showing the effect of exposure to ambient air after selected time intervals for a unhydrated samples, and samples hydrated for b $10 \mathrm{~min}, \mathbf{c} 30 \mathrm{~min}$, d $4 \mathrm{~h}$ and $\mathrm{e} 8 \mathrm{~h}$. The spectrum after $10 \mathrm{~min}$ of exposure within each hydration series was subtracted from all of

The total amount of carbonates produced appears to increase for longer hydration durations, as indicated by the convergence limit of the curves in Fig. 3. At these experimental conditions it must therefore be easier for the carbon dioxide to react with the calcium in the hydrated cement than the calcium in the unhydrated clinker for short hydration times. This is reasonable, as the clinker is much denser and thus less accessible than the early formed hydration products. The absolute amount of carbonates formed was not determined. However, an estimate was made by integrating

the subsequent spectra to remove all signatures that are not the result of exposure. The assignments and characterizations of the peaks and bands, marked with $I-X$ in the spectra, are presented in Table 1.

the peak areas in the interval $1,300-1,700 \mathrm{~cm}^{-1}$ in the original spectra without subtraction. The peak area is roughly doubled after 4 days of exposure to a humid $\mathrm{CO}_{2}$ atmosphere. A similar increase is also seen under ambient conditions after 19 days. Ideally, the integrated area is proportional to the concentration (Griffiths et al. 2007). This suggests that the original $\sim 10 \%$ by mass of $\mathrm{CaCO}_{3}$ in the cement investigated is approximately doubled. However, infrared spectroscopy is a surface technique that only penetrates a few wave lengths into the material, i.e. a few 


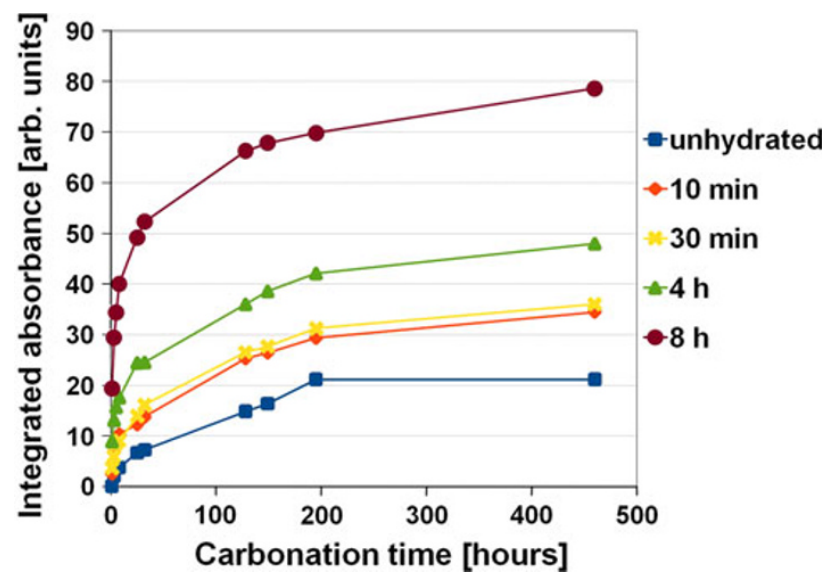

Fig. 3 Integrated peak areas for unhydrated and hydrated samples exposed to ambient air as a function of exposure time. The integration range was $1,300-1,700 \mathrm{~cm}^{-1}$ (marked as dotted lines in Fig. 2), where the zero-level was set at $1,300 \mathrm{~cm}^{-1}$. The sample exposed for $10 \mathrm{~min}$ was used as reference for each hydration time.

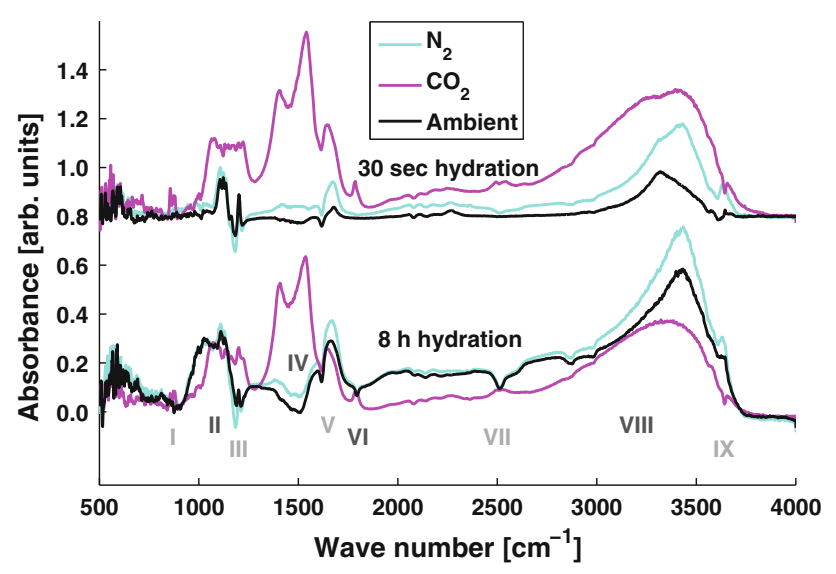

Fig. 4 DR-FTIR spectra showing the impact of the $\mathrm{N}_{2}$ and $\mathrm{CO}_{2}$ atmospheres on hydrated dried cement paste. A hydrated and unexposed sample is given as a reference. The spectrum of an unhydrated and unexposed cement sample was used as a background for all of the hydrated spectra shown. The black lines are the infrared spectra of the hydrated unexposed samples. The cyan lines are the infrared spectra of the samples after exposure to a moist $\mathrm{N}_{2}$ atmosphere for 3 days. The magenta lines are the infrared spectra of the samples after exposure to a moist $\mathrm{CO}_{2}$ atmosphere for 4 days. The assignments and characterizations of the peaks and bands, marked with $I-X$ in the spectra, are presented in Table 1.

micrometers. If the limestone originally present in the cement consists of larger particles, and the carbonates formed during exposure is formed either as small particles or as shells around existing structures, then the total amount of carbonate is smaller. Since the small characteristic water peak at $1,650 \mathrm{~cm}^{-1}$ lies in the region $1,300-1,700 \mathrm{~cm}^{-1}$, it will also affect the result to some extent.

In all of the samples, except for the unhydrated cement, the carbonate is easily seen with DR-FTIR spectroscopy within an hour of exposure to ambient air. Consequently, freshly cast cement is sensitive to carbonation; to prevent

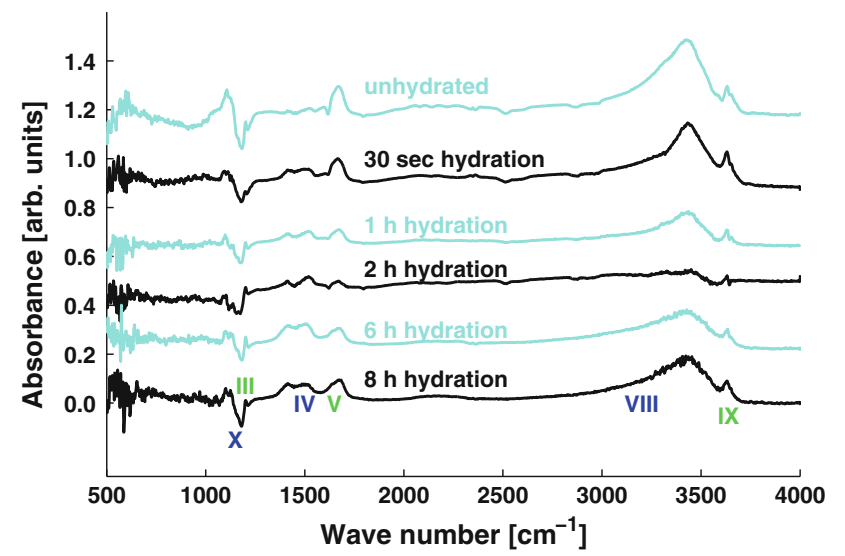

Fig. 5 Enhanced DR-FTIR spectra showing the effect of exposure to a humid $\mathrm{N}_{2}$ atmosphere. The spectra of hydrated unexposed samples were subtracted from the spectra of the samples exposed to humid $\mathrm{N}_{2}$, cancelling the effect of hydration on the samples. The assignments and characterizations of the peaks and bands, marked with $I-X$ in the spectra, are presented in Table 1.

interference of carbonate formation during analysis samples should be handled to minimize their exposure to carbon dioxide. However, as the samples are in powdered form their reactive surface area is very large. Indeed, samples in their cast form will probably be more resistant to carbonation as there is less exposed surface area and the carbon dioxide will have to diffuse into the sample.

The effect of the moist $\mathrm{N}_{2}$ atmosphere was small, and there was no sign of hydration of the clinker phases, which is consistent with previous results (Mejlhede Jensen et al. 1999). Some transformations of sulfates seem to occur, emphasized by a shift in absorbance of the $\mathrm{S}-\mathrm{O}$ stretching between 1,100 and $1,200 \mathrm{~cm}^{-1}$. The spectrum of the product fits well with that of ettringite. However, it is interesting to note that the amount of ettringite does not uniformly increase or decrease with increased hydration time. The ettringite decreases during the first $2 \mathrm{~h}$ of hydration, after which it increases again for longer hydration times. This implies that there are only some sulfate species that can react with the moisture in the atmosphere, and that the amount of these species will vary during the early hydration of the cement.

In a moist atmosphere the $\mathrm{CO}_{2}$ reacts with calcium extracted from both the clinker and the calcium silica gel. Even though sulfate phases, such as ettringite, can be carbonated, this was not observed in this experiment. This can be concluded because there are no observable signatures of the calcium sulfate species, such as gypsum, formed as a byproduct of the carbonation (Grounds et al. 1988; Xiantuo and Ruizhen 1994).

The consumption of $\mathrm{C}-\mathrm{S}-\mathrm{H}$ is seen as dips in the $8-\mathrm{h}$ hydration spectrum in Fig. 6. This is apparent both in the $\mathrm{OH}$-stretching region above $3,000 \mathrm{~cm}^{-1}$ and in the region 900-1,100 $\mathrm{cm}^{-1}$ (overlapping with the $\mathrm{CaCO}_{3}$ band at $1,080 \mathrm{~cm}^{-1}$ ). The remaining silica gives an absorption profile resembling condensed silica (Ylmén et al. 2008) with a broad band at $1,200 \mathrm{~cm}^{-1}$. The spectrum after $30 \mathrm{~s}$ of 


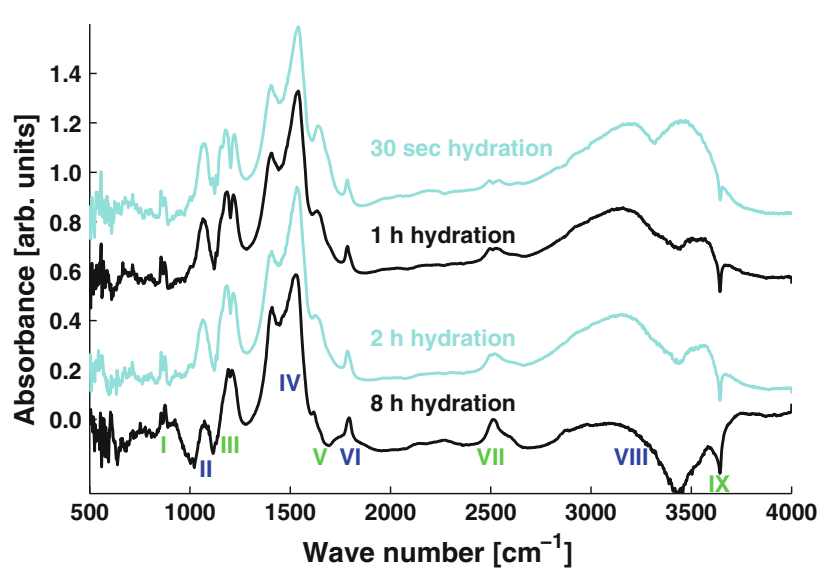

Fig. 6 Enhanced DR-FTIR spectra showing the effect of exposure to a humid $\mathrm{CO}_{2}$ atmosphere. The spectra of hydrated unexposed samples were subtracted from the spectra of the samples exposed to humid $\mathrm{CO}_{2}$, cancelling the effect of hydration on the samples. The assignments and characterizations of the peaks and bands, marked with $I-X$ in the spectra, are presented in Table 1.

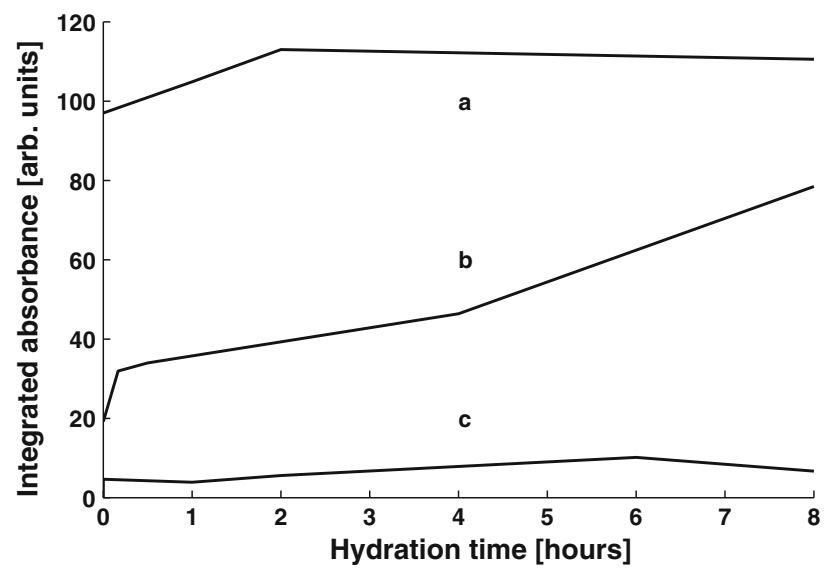

Fig. 7 The variation of the carbonation rate versus hydration time under three environmental conditions during the first 8 h of hydration. The relative amount of carbonation was determined from the integrated area between 1,300 and $1,700 \mathrm{~cm}^{-1}$, where the zero-level was set as a straight line between the endpoints of the integrated area. (a) Humid $\mathrm{CO}_{2}$ atmosphere. (b) Exposure to ambient air for 19 days. (c) Humid $\mathrm{N}_{2}$ atmosphere.

hydration, see Fig. 6, has no dips due to consumption of $\mathrm{C}-\mathrm{S}-\mathrm{H}$, since the hydration time is too short to form $\mathrm{C}-\mathrm{S}-\mathrm{H}$. Here condensed silica is formed as a by-product since calcium is extracted from the clinker by the $\mathrm{CO}_{2}$.

It was noted that there is also a narrow peak at $1,200 \mathrm{~cm}^{-1}$ for the unexposed samples in Fig. 4. The peak is larger in the 30-s hydrated sample than in the 8-h hydrated sample. Although the peak was not assigned in this work, the compound absorbing at this wavelength is probably crystalline since the peak is very narrow. This signature has been observed in earlier work (Ylmén et al. 2008) and was there found to be correlated with a broader peak at $\sim 3,300 \mathrm{~cm}^{-1}$. This correlation is supported here, as there is a large peak centred at $3,310 \mathrm{~cm}^{-1}$ seen in the unexposed sample hydrated for $30 \mathrm{~s}$ in Fig. 4. When the hydrated samples are exposed to a humid $\mathrm{N}_{2}$ atmosphere there seems to be a slightly increased amount of this unidentified compound as the peak is visible in Fig. 5. However, the humid $\mathrm{CO}_{2}$ atmosphere seems to decompose the compound, since the signature is seen as a narrow dip at $1,200 \mathrm{~cm}^{-1}$ superimposed on the broader peak at the same position as a result of the formation of silica in Fig. 6 .

It has previously been shown that the formation of $\mathrm{CaCO}_{3}$ in aqueous solution normally produces calcite and/or vaterite as final products (Shivkumara et al. 2006; Clarkson et al. 1992). However, the signature of the $\mathrm{CaCO}_{3}$ formed in this study does not exactly match any of the spectra of calcite, vaterite or aragonite (Xyla and Koutsoukos 1989). However, there are also hydrated forms of $\mathrm{CaCO}_{3}$, such as monohydrocalcite $\left(\mathrm{CaCO}_{3} \cdot \mathrm{H}_{2} \mathrm{O}\right)$, ikaite $\left(\mathrm{CaCO}_{3} \cdot 6 \mathrm{H}_{2} \mathrm{O}\right)$ and amorphous calcite (Lam et al. 2007; Andersen and Ljerka Brečević 1991; Coleyshaw et al. 2003). The shape of the large carbonate band, at $1,400-1,600 \mathrm{~cm}^{-1}$, with two distinct peaks and the increase of water at $1,650 \mathrm{~cm}^{-1}$ is similar to the infrared spectrum of both monohydrocalcite and amorphous calcium carbonate (Lam et al. 2007; Andersen and Ljerka Brečević 1991; Coleyshaw et al. 2003).

The formation of $\mathrm{CaCO}_{3}$ in cement is a complex process that can involve reactions at various particle surfaces. The mechanism of these reactions is not yet fully understood. In the early stages the carbonates formed could be considered amorphous, since the crystallites have not yet developed a well-defined structure. The broadening of the band observed at $1,080 \mathrm{~cm}^{-1}$ indicates a less ordered structure because the peak is expected to be narrow if the phases are crystalline. This is consistent with the infrared spectra of synthesized amorphous calcium carbonate (Lam et al. 2007; Andersen and Ljerka Brečević 1991). The broadening is a sign of a more varying environment for the carbonate ion than that present in the crystalline structures. At later stages a more crystalline product can be expected.

The DR-FTIR spectroscopy technique relies on the vibration modes of characteristic groups in a compound, i.e. not on the crystallinity of the sample. Consequently, the characteristic vibration peaks in the region 1,300-1,700 $\mathrm{cm}^{-1}$ are representative of all carbonate species irrespective of the chemical and physical form. Thus DR-FTIR spectroscopy is a very suitable method for monitoring the formation of compounds such as carbonates in cement. Complementary methods such as Raman spectroscopy, thermogravimetric analysis and scanning electron microscopy could be used to bring more detailed information about the formed carbonate species. Thermodynamic computer calculations may also be an important tool to understand the complex carbonation processes in cement. However, these techniques are not within the scope of this study, but is an interesting topic for future work.

\section{Conclusions}

A method combining DR-FTIR spectroscopy with a previously developed freeze drying technique was applied 
successfully to investigate the carbonation of cement samples during selected hydration stages. The method makes it possible to monitor the formation of carbonate phases during various carbonation conditions. Applying this method on cement, hydrated up to $8 \mathrm{~h}$, it was found that in ambient air both the $\mathrm{C}-\mathrm{S}-\mathrm{H}$ and $\mathrm{Ca}(\mathrm{OH})_{2}$ show carbonation; longer hydration time leads to more carbonation. As cement samples are exposed in a humid $\mathrm{CO}_{2}$ atmosphere, the $\mathrm{C}-\mathrm{S}-\mathrm{H}$ carbonates to such an extent that it decomposes to $\mathrm{CaCO}_{3}$ and silica. When cement samples were exposed in a humid $\mathrm{N}_{2}$ atmosphere, no carbonation was observed with this technique. However, there was some ettringite formation.

\section{Open Access}

This article is distributed under the terms of the Creative Commons Attribution License which permits any use, distribution, and reproduction in any medium, provided the original author(s) and the source are credited.

\section{References}

Andersen, F. A., \& Ljerka Brečević, L. (1991). Infrared spectra of amorphous and crystalline calcium carbonate. Acta Chemica Scandinavica, 45, 1018-1024.

Björnström, J. (2005). Influence of nano-silica and organic admixtures on cement hydration: A mechanistic investigation. $\mathrm{PhD}$ thesis, Department of Chemistry, Göteborg University, Gothenburg, Sweden.

Clarkson, J. R., Price, T. J., \& Adams, C. J. (1992). Role of metastable phases in the spontaneous precipitation of calcium carbonate. Journal of the Chemical Society, Faraday Transactions, 88(2), 243-249.

Coleyshaw, E. E., Crump, G., \& Griffith, W. P. (2003). Vibrational spectra of the hydrated carbonate minerals ikaite, monohydrocalcite, lansfordite and nesquehonite. Spectrochimica Acta Part A, 59, 2231-2239.

Delgado, A. H., Paroli, R. M., \& Beaudoin, J. J. (1996). Comparison of IR techniques for the characterization of construction cement minerals and hydrated products. Applied Spectroscopy, 50(8), 970-976.

Frech, R., Wang, E. C., \& Bates, J. B. (1980). The I.R. and Raman spectra of $\mathrm{CaCO}_{3}$ (aragonite). Spectrochimica Acta, 36A, 915-919.

Griffiths, P. R., de Haseth, J. A., \& Fourier, (2007). Transform infrared spectrometry (2nd ed., p. 349). Hoboken, NJ: Wiley.

Grounds, T., Midgley, H. G., \& Nowell, D. V. (1988). Carbonation of ettringite by atmospheric carbon dioxide. Thermochimica Acta, 135, 347-352.

Gunasekaran, S., Anbalagan, G., \& Pandi, S. (2006). Raman and infrared spectra of carbonates of calcite structure. Journal of Raman Spectroscopy, 37, 892-899.

Houst, Y. F. (1996). The role of moisture in the carbonation of cementitious materials. Internationale Zeitschrift für Bauinstandsetzen, 1, 49-66.
Lam, R. S. K., Charnock, J. M., Lennie, A., \& Meldrum, F. C. (2007). Synthesis-dependant structural variations in amorphous calcium carbonate. CrystEngComm, 9, 1226-1236.

Mejlhede Jensen, O., Freiesleben Hansen, P., Lachowski, E. E., \& Glasser, F. P. (1999). Clinker mineral hydration at reduced relative humidities. Cement and Concrete Research, 29, 1505-1512.

Mollah, M. Y. A., Kesmez, M., \& Cocke, D. L. (2003). An $\mathrm{X}$-ray diffraction (XRD) and Fourier transform infrared spectroscopic (FT-IR) investigation of the long-term effect on the solidification/stabilization $(\mathrm{S} / \mathrm{S})$ of $\operatorname{arsenic}(\mathrm{V})$ in Portland cement type-V. Science of the Total Environment, 325, 255-262.

Pajares, I., Martínez-Ramírez, S., \& Blanco-Varela, M. T. (2003). Evolution of ettringite in presence of carbonate, and silicate ions. Cement \& Concrete Composites, 25, 861-865.

Richard, T., Mercury, L., Poulet, F., \& d'Hendecourt, L. (2006). Diffuse reflectance infrared Fourier transform spectroscopy as a tool to characterise water in adsorption/confinement situations. Journal of Colloid and Interface Science, 304, $125-136$

Rutt, H. N., \& Nicola, J. H. (1974). Raman spectra of carbonates of calcite structure. Journal of Physics C Solid State Physics, 7, 4522-4528.

Shivkumara, C., Singh, P., Gupta, A., \& Hegde, M. S. (2006). Synthesis of vaterite $\mathrm{CaCO}_{3}$ by direct precipitation using glycine and L-alanine as directing agents. Materials Research Bulletin, 41, 1455-1460.

Trezza, M. A., \& Lavat, A. E. (2001). Analysis of the system $3 \mathrm{CaO} \cdot \mathrm{Al}_{2} \mathrm{O}_{3}-\mathrm{CaSO}_{4} \cdot 2 \mathrm{H}_{2} \mathrm{O}-\mathrm{CaCO}_{3}-\mathrm{H}_{2} \mathrm{O}$ by FT-IR spectroscopy. Cement and Concrete Research, 31, 869-872.

Vagenas, N. V., Gatsouli, A., \& Kontoyannis, C. G. (2003). Quantitative analysis of synthetic calcium carbonate polymorphs using FT-IR spectroscopy. Talanta, 59, 831-836.

Vazquez-Moreno, T., \& Blanco-Varela, M. T. (1981). Table of infrared frequencies and absorption spectra of compound related to cement chemistry. Materiales de Construccion, 182, 31-48.

Xiantuo, C., \& Ruizhen, Z. (1994). Kinetic study of ettringite carbonation reaction. Cement and Concrete Research, 24, 1383-1389.

Xyla, A. G., \& Koutsoukos, P. G. (1989). Quantitative analysis of calcium carbonate polymorphs by infrared spectroscopy. Journal of the Chemical Society, Faraday Transactions, 185(10), 3165-3172.

Ylmén, R., Jäglid, U., Steenari, B.-M., \& Panas, I. (2009). Early hydration and setting of Portland cement monitored by IR, SEM and Vicat Techniques. Cement and Concrete Research, 39, 433-439.

Ylmén, R., Larsson, K., Jäglid, U., Panas, I., \& Steenari, B.-M. (2008). DR-FTIR method for the study of early hydration of cement. In Conference Proceedings for "SCC 2008: Challenges and Barriers to Application, Chicago, IL, November 10-12.

Yu, P., Kirkpatrick, R. J., Poe, B., McMillan, P. F., \& Cong, X. (1999). Structure of calcium silicate hydrate $(\mathrm{C}-\mathrm{S}-\mathrm{H})$ : near-, mid-, and far-infrared spectroscopy. Journal of American Ceramic Society, 82(3), 742-748. 